\title{
Estudo das propriedades físicas de um biomaterial com nova composição de wollastonita e beta fosfato tricálcico para regeneração óssea após implante in vivo
}

\author{
Study of the physical properties of a biomaterial with a new composition of \\ wollastonite and beta-tricalcium phosphate for bone regeneration after implantation \\ in vivo
}

Mauricio Mitsuo Monção ${ }^{1^{*}}$, Fabiana Paim Rosa²

\begin{abstract}
${ }^{1}$ Doutorando do Programa de Pós-graduação em Processos Interativos de Órgãos e Sistemas - ICS/UFBA. Professor do Departamento de Tecnologia em Saúde e Biologia do Instituto Federal de Educação, Ciência de Tecnologia da Bahia.; ' Doutora em Periodontia. Professora Adjunta de Graduação e Pós-Graduação em Processos Interativos dos Órgãos e Sistemas - ICS/UFBA. Coordenadora do Laboratório de Bioengenharia Tecidual e Biomateriais do ICS/ UFBA.
\end{abstract}

\begin{abstract}
Resumo
Introdução: associadas à composição química, as propriedades físicas dos biomateriais como formato, dimensões e porosidade, são fatores que influenciam na biocompatibilidade, biodegradabilidade e nos potenciais osteoindutivo e osteocondutores. Objetivo: identificar modificações físicas no formato, dimensões e porosidade de um biomaterial com nova composição de wollastonita e beta fosfato tricálcico, implantado em defeitos ósseos críticos em calvária de ratos. Metodologia: trata-se de um estudo exploratório, com um biomaterial compósito, antes e após a sua implantação in vivo. Utilizou-se explantes cirúrgicos de calvárias de ratos que receberam implantes em defeito ósseo crítico. Os animais foram distribuídos em 3 grupos experimentais aleatoriamente, compostos por 5 animais cada, e avaliados com 15, 45 e 120 dias. Os grupos foram denominados: G0-biomaterial; GI-15 dias; GII-45 dias; e, GIII-120 dias. As amostras foram micrografadas em microscópio eletrônico de varredura, com diferentes magnificações. Utilizouse o software livre ImageJ para processamento das imagens e análise das partículas e poros. Resultados: a distribuição espacial do biomaterial promoveu preenchimento completo do defeito ósseo crítico. Micrografias com diferentes magnificações permitiu identificar modificações na área de contato entre grânulos, diminuição dos poros intergranular, aumento da área ocupada pelos poros e diminuição das partículas nos grânulos. Nos grupos GII e GIII, identificou-se formação de componentes orgânicos na superfície do implante. Conclusão: houve modificações físicas no formato, dimensões horizontais, distribuição espacial e porosidade da superfície dos grânulos do biomaterial, relacionadas com a biodegradabilidade e o potencial osteoindutivo e osteocondutor do biomaterial. Palavras-chave: Biomaterial. Compósitos. Regeneração óssea. Microscopia eletrônica de varredura.
\end{abstract}

\footnotetext{
Abstract

Introduction: associated with the chemical composition, physical properties of biomaterials related to their format, dimensions and porosity, are factors that influence on biocompatibility, biodegradability and osteoinductive and osteoconductive potential. Objective: identify physical changes in the format, dimensions and porosity of biomaterial with new composition of wollastonite and beta tricalcium phosphate, implanted in critical bone defects in calvaria of rats. Methodology: this is an exploratory study, with a composite biomaterial before and after its implantation in vivo. Used surgical explants of rat calvarium that received biomaterial implants into the critical bone defect. The animals were divided into 3 experimental groups of random distribution, composed of 5 animals each, and evaluated for 15, 45 and 120 days. The groups were named: G0-Biomaterial; GI-15 days; GII-45 days; and, GIII-120 days. The samples were studied by micrography in scanning electronic microscope with different magnifications. It was used the free software ImageJ to image processing and particles and pores analysis. Results: the spatial distribution of the biomaterial promoted full filling of the critical bone defect. Micrographs with different magnifications allowed to identification of modifications in the area of contact between granules, decrease of the intergranular pores, increase of the area occupied by the pores and decrease of the particles in the granules. In GII, and GIII groups, it was identified formation of organic components on the surface of the implant. Conclusion: there were physical modifications in the format, horizontal dimensions, spatial distribution and porosity of the biomaterial, related to the biodegradability and the osteoinductive and osteoconductive

Correspondente/Corresponding: * Mauricio Mitsuo Monção - Instituto Federal de Educação, Ciência e Tecnologia da Bahia DTSBio - Campus potential of the biomaterial.

Keywords: Biomaterial. Composites. Bone regeneration. Scanning electronic microscopy.
} de Salvador - End: Rua Emídio dos Santos, s/n, Barbalho, 40301-015 - Salvador-BA. - Tel: (71) 99176-0072. - Email: maurimitsuo@yahoo. com.bre mauriciomitsuo@ifba.edu.br 


\section{INTRODUÇÃO}

Ante a perda de tecido ósseo, em muitas situações clínicas, necessita-se do uso de materiais substitutos biocompativeis para o local com tecido danificado. Por isso, pesquisas da bioengenharia tecidual buscam alternativas com novos biomateriais que apresentem maiores potenciais para regeneração e reparo tecidual ósseo (CAMPOS, 2015; DOROZHKIN, 2007).

No entanto, de acordo com Garcia-Gareta, Coathup e Blunn (2015), o implante com osso esponjoso autógeno ainda é o tratamento padrão ouro, cujas propriedades de osteogênese, osteocondução e osteoindução são mantidas no autoenxerto, além da vantagem de não transmissão de doenças ou reações autoimunes. Porém, o uso de osso autógeno apresenta desvantagens, como disponibilidade limitada, e consequências do procedimento, como risco de infecção, aumento do tempo pós-operatório, dor no local doador e aumento de custo. Por isso, faz-se necessário o desenvolvimento de novas alternativas que substituam implantes com osso autógeno e que apresentem propriedades físico-químicas favoráveis ao processo de regeneração e reparação óssea (TAYLOR; KHAN; LAURENCIN, 2009).

Atualmente, destacam-se as cerâmicas biocompatíveis e biodegradáveis como implantes que atuam temporariamente, sendo gradualmente substituídas por novo tecido ósseo. Dentro desse grupo, a wollastonita (W) e o beta fosfato tricálcio ( $\beta$-TCP) são conhecidos por apresentarem propriedades favoráveis ao processo de regeneração óssea. Estudo de Sainitya et al. (2015) concluiu que a adição de $\mathrm{W}$ aumentou a resitência mecânica de um bimaterial compósito, bem como houve promoção da diferenciação celular de osteoblastos, favorecendo o potencial osteogênico. Já estudos com $\beta$-TCP são amplamente divulgados há mais de duas décadas, pois se trata de um material biocompatível, biodegradável, com propriedades bioativas e de osteocondução (MATSUMOTO et al., 2009).

A partir do conhecimento sobre os potenciais da We do $\beta$-TCP, produziu-se um biomaterial com nova composição físico-químicas, que buscou agregar propriedades individuais de cada um dos referidos materiais. Sabe-se que, associada à composição química do biomaterial, suas propriedades físicas, como forma, dimensões, distribuição espacial e presença de poros, são fatores que influenciarão na biocompatibilidade, biodegradação e nos potenciais osteoindutivo e osteocundutor (CONZ et al. 2010). Nesse contexto, o presente estudo teve por objetivo realizar um estudo exploratório para identificar modificações nas referidas propriedades físicas do biomaterial com nova composição de W e $\beta$-TCP, implantado em defeitos ósseos críticos em calvária de ratos.

\section{METODOLOGIA}

Trata-se de um estudo exploratório sobre um biomaterial com nova composição de $W$ e $\beta$-TCP, antes e após a implantação em defeitos ósseos críticos em calvária de ratos. Os materiais estudados pertencem ao banco de amostras do Laboratório de Bioengenharia Tecidual e Biomateriais, do Instituto de Ciências da Saúde, da Universidade Federal da Bahia, e procedem de um estudo anterior, realizado pelo grupo de pesquisa do referido laboratório, com a devida aprovação do Comitê de Ética no Uso de Animais, com protocolo número 078-2015 CEUA/UFBA.

O biomaterial com nova composição de $W$ e $\beta$-TCP foi desenvolvido e fabricado por Helicon medical S.L. (Madrid-Espanha), por convênio firmado entre o Consejo Superior de Investigaciones Científicas (CSIC), o Instituto de Cerámica y Vidrio (Madri-Espanha), e a Universidade Federal da Bahia, UFBA. Trata-se de um material bifásico cristalino, composto por $40 \%$ de pseudowollastonita e $60 \%$ de beta fosfato tricálcico, obtido em condições de não equilíbrio, produzido por sinterização, originando fases amorfas de natureza vítrea. Esse biomaterial tem uma área superficial específica de $0,36 \pm 0,02 \mathrm{~mm}^{2} / \mathrm{g}$ por grânulos, com tamanho que varia de 400-600 $\mu \mathrm{m}$.

Inicialmente, determinaram-se os 4 grupos de estudo sendo: G0 - biomaterial; GI-15 dias; GII-45 dias; e, GIII-120 dias, que correspondem ao novo biomaterial antes e após implante, com 3 diferentes pontos biológicos. O grupo G0 foi composto por uma amostra aleatória de 0,60g de grânulos do biomaterial, pertencentes ao mesmo lote de fabricação dos utilizados nos implantes dos demais grupos de estudo.

Para as amostras dos grupos GI, GII e GIII, obtiveram-se explantes cirúrgicos de calvárias de ratos, a partir de 3 grupos experimentais de distribuição aleatória, compostos por 5 animais cada, de acordo com diferentes pontos biológicos após implantes do biomaterial, que correspondem aos grupos Grupo I - 15 dias, Grupo II - 45 dias, e Grupo III - 120 dias. O biomaterial foi implantado em defeitos ósseos circulares, confeccionados nas calvárias dos respectivos ratos, e transfixado com $8,5 \mathrm{~mm}$ de diâmetro e aproximadamente $0,8 \mathrm{~mm}$ de espessura, na porção mediana. Os animais foram eutanasiados nos pontos biológicos de 15, 45 e 120 dias, de acordo com os grupos de estudo a que pertenciam, e as calvárias retiradas cirurgicamente (explantes) foram conservadas em formol tamponado $4 \%$, condicionadas em geladeira com temperatura entre 4 e $8^{\circ} \mathrm{C}$. Posteriormente, os fragmentos dos explantes, com dimensões horizontais de $1 \mathrm{~mm}$ de largura por $1 \mathrm{~cm}$ de comprimento, foram retirados com auxílio de um disco diamantado, acoplado a um motor de alta rotação, com cortes no sentido coronal em relação às calvárias. Esses fragmentos foram lavados com tampão fosfato $0,1 \mathrm{M}(3 \mathrm{x})$, por 10 minutos cada, e submetidos a um processo de desidratação em álcool, com concentrações crescentes de $60 \%, 70 \%, 80 \%, 90 \%$, com 10 min cada, e finalmente com álcool 100\% (3x), com 10 minutos cada.

Após essa etapa inicial, as amostras dos 4 grupos de estudo foram levadas para o Laboratório de Caracterização de Materiais (LCM), do Instituto Federal de Educação, 
Ciência e Tecnologia da Bahia, para a obtenção das micrografias por microscopia eletrônica de varredura (MEV). As amostras foram colocadas em uma fita de carbono dupla face, fixadas em um porta amostra, na forma de disco em liga de alumínio, com superfície lisa. Foram então colocadas em um metalizador (Quorum Technologies, modelo Q150R) e submetidas ao processo de metalização por pulverização catódica, com deposição de um filme de ouro sobre a superfície das amostras a serem analisadas. Os parâmetros de deposição iônica estabelecidos foram os seguintes: temperatura ambiente de $25^{\circ} \mathrm{C}$, corrente de $20 \mathrm{~mA}$, tensão de $2 \mathrm{kV}$ e tempo de deposição de 120 segundos, fornecendo um filme de ouro na superfície das partículas da ordem de $25 \mathrm{~nm}$. Para obtenção das micrografias, o presente estudo utilizou-se do microscópio eletrônico de varredura da marca TESCAN, modelo VEGA $3 \mathrm{LMU}$, pelo método de elétrons secundários, com distância de trabalho de $15 \mathrm{~mm}$ e tensão de aceleração dos elétrons de $10 \mathrm{kV}$.

As micrografias foram obtidas com diferentes aumentos da MEV. Para os grupos GI, GII e GIII, as micrografias foram realizadas em porção mediana dos explantes cirúrgicos. As imagens obtidas foram processadas e analisadas e com auxílio do software livre ImageJ (versão Java 1.7 32-bit) de domínio público. Também, utilizou-se o software para análise quantitativa das partículas e poros dos grupos $\mathrm{G} 0$ e $\mathrm{Gl}$.

\section{RESULTADOS}

O biomaterial com nova composição de W e $\beta$-TCP apresentou modificações físicas progressivas, identificadas nos diferentes pontos biológicos. As micrografias dos grânulos (G0), com ampliação de 50 vezes (Figura 1) da $\mathrm{MEV}$, mostram formas sólidas, variadas e aleatórias, com dimensões horizontais na superfície na faixa entre $400 \mu \mathrm{m}$ e $1.000 \mu \mathrm{m}$, identificadas nos grânulos L1 a L7. Trata-se de grânulos irregulares, multifacetados e angulares, com superfície rugosa e porosa.

Nas micrografias com aumentos de 1.000, 5.000 e 10.000 vezes (Figura 2), identificaram-se aspectos detaIhados da microestrutura porosa dos grânulos do compósito, formada pelas micropartículas interconectadas do biomaterial granulado.

A distribuição espacial dos grânulos do biomaterial com nova composição de W e $\beta$-TCP promoveu o preenchimento completo dos defeitos ósseos críticos. Micrografias com aumento de 100 vezes demonstram nos grupos GI e GIl a distribuição espacial aleatória dos grânulos na superfície do implante (Figura 3). No grupo GI, correspondente ao ponto biológico de 15 dias, observam-se individualmente os grânulos, bem como áreas de contato entre eles. É possível observar locais com presença de poros intergranular. O grupo GII, correspondente ao ponto biológico de 45 dias, o local que recebeu o implante apresentou-se com aspecto mais liso e uniforme em relação ao Gl. Porém, ainda é possível diferenciar locais onde os grânulos foram depositados. As áreas de contato e a porosidade intergranular não são mais visíveis. No grupo III, correspondente ao ponto biológico de 120 dias, a imagem com 500 vezes de aumento demonstra a superfície que recebeu o implante com aspecto liso e ainda mais uniforme em relação aos outros grupos, GI e GII. Já não se observou, no referido aumento da MEV, presença dos grânulos ou partículas do biomaterial na superfície do implante (Figura 3).

Os resultados obtidos também possibilitaram a identificação das modificações progressivas nas dimensões e formato das partículas, bem como na porosidade do biomaterial, quando comparadas as micrografias dos grupos de estudos, nos diferentes pontos biológicos. Micrografias com aumento de 5 mil vezes são mostradas na Figura $4 \mathrm{e}$ permitem identificar as mudanças no biomaterial depositado no defeito ósseo crítico. Para o G0, sem contato com tecidos e fluido biológico, foi possível identificar as micropartículas angulares interconectadas e a abundância de microporos presentes na superfície dos grânulos do biomaterial. Trata-se das características correspondentes ao material do tipo vitrocerâmico, obtido por processo de sinterização. Na micrografia da amostra do grupo Gl (15 dias após a implantação), foi possível identificar nítidas mudanças físicas no formato das partículas, que são observadas parcialmente conectadas à superfície do grânulo e passaram a apresentar aspectos esféricos. Também é possível observar aumento nos tamanhos dos poros e identificar visualmente a diminuição da quantidade das partículas menores. Para as amostras dos grupos GII e GIII (45 e 120 dias) não foi possível observar a porosidade característica do biomaterial, por tratar-se de pontos biológicos onde componentes orgânicos já haviam recoberto os grânulos no local do implante (Figura 5).

A avaliação mais detalhada nas modificações da superfície das micropartículas, bem como da porosidade e que compõem o biomaterial com nova composição de $W$ e $\beta$-TCP, foi realizada por meio do programa ImageJ (Sheffield, 2007). Excluíram-se dessa avaliação amostras dos grupos GII e GIII, pois, conforme já apresentado, nos respectivos pontos biológicos não foi mais identificada a porosidade característica dos grânulos do novo biomaterial na superfície dos explantes. A Figura 5 apresenta as micrografias originais dos grupos $\mathrm{GO}$ e $\mathrm{Gl}$ e as respectivas imagens com processamento para alto contraste, obtidas por meio da ferramenta Threshold (Limiarização), que transformou as micrografias em imagens binárias, com valor de pixels $=255$ para imagens claras e valor de pixels $=0$ para imagens mais escuras (5B e 5E). Para análise das partículas, a ferramenta convert to mask foi usada para converter o valor de pixels $=255$ em imagens escuras, e valor de pixels $=0$ para imagens mais claras $(5 C$ e $5 F)$. 
Figura 1 - Micrografias da MEV dos grânulos do biomaterial composto de W e B-TCP, com 100 vezes de aumento. (1A) Observa-se o formato dos grânulos, variação de tamanhos e disposição aleatórias. Identifica-se componentes multifacetados e angulares. (1B) É demonstrado medidas nas dimensões horizontais da superfície dos grânulos na faixa entre $400 \mu \mathrm{m}$ e $1.000 \mu \mathrm{m}$.

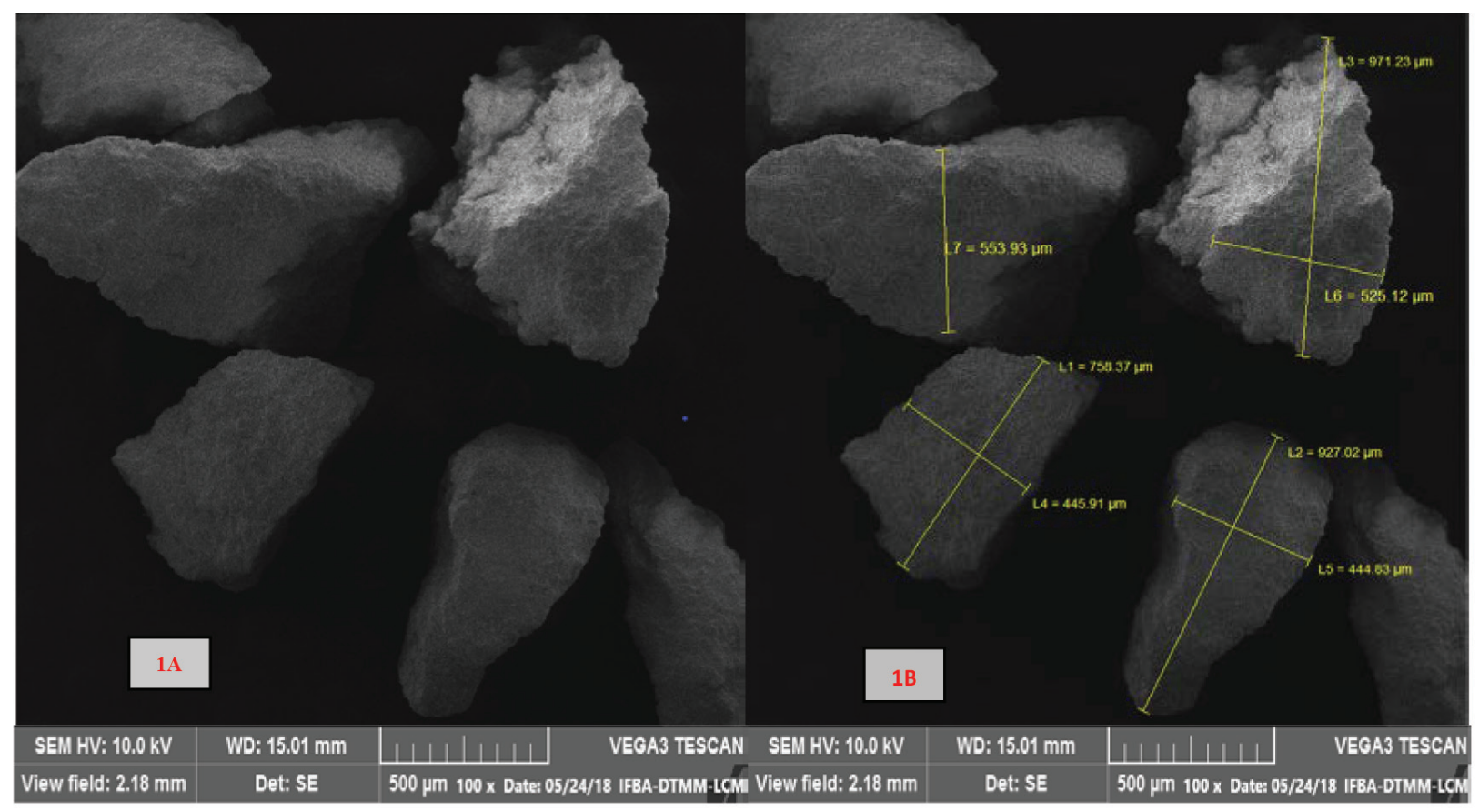

Fonte: Elaboração dos autores.

Figura 2 - As imagens com aumentos 5.000 e 10.000 vezes (2A e 2B) respectivamente, correspondem a micrografias da superfície das amostras de grânulos do biomaterial composto de W e B-TCP. É possível identificar aspectos detalhados da microestrutura porosa, formada pelas micropartículas interconectadas do biomaterial granulado.

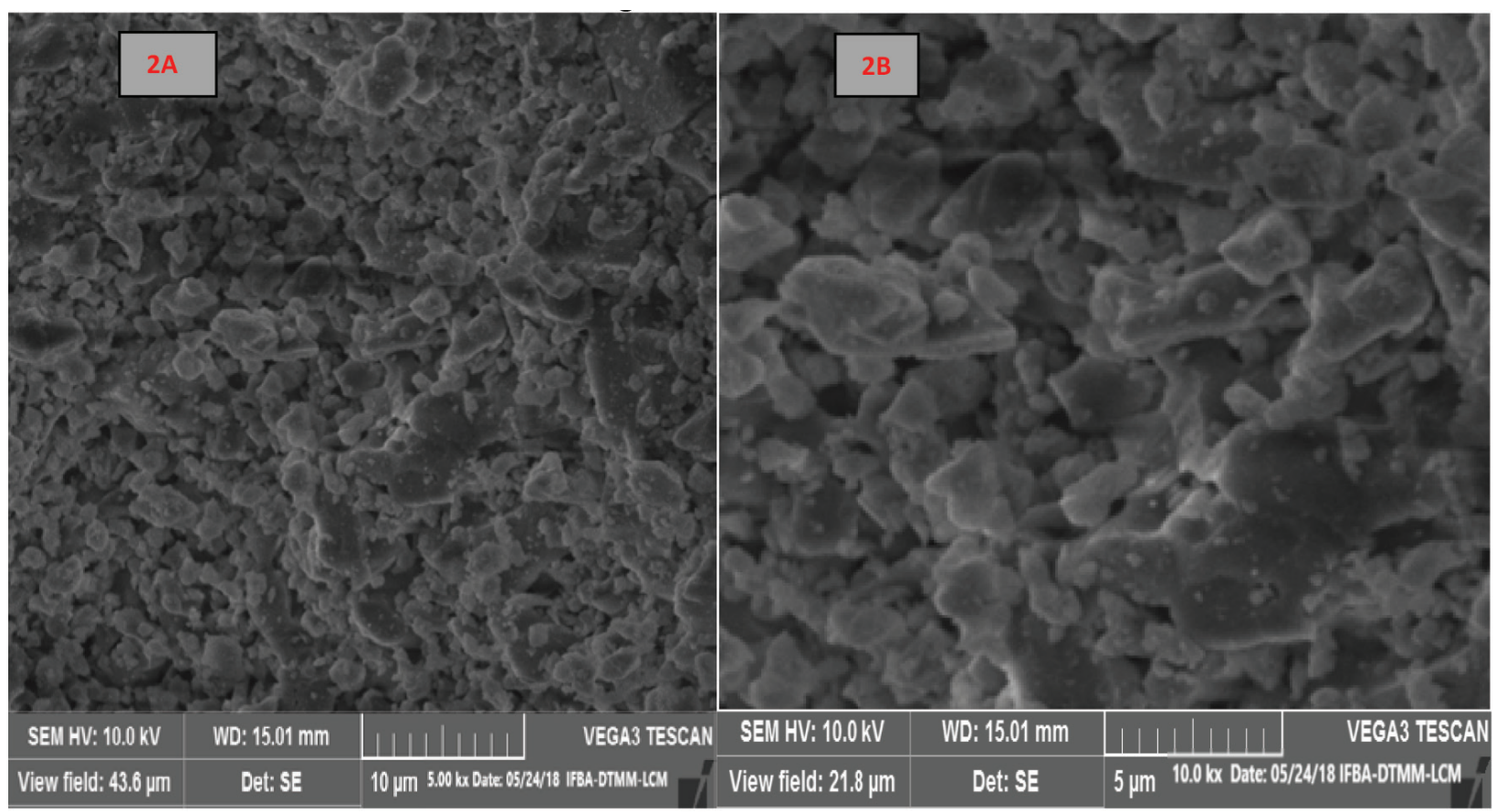

Fonte: Elaboração dos autores. 
Figura 3 - Micrografias de três amostras de explantes cirúrgicos, obtidos em diferentes pontos biológicos, sendo Gl e Gll com 100 vezes de aumento, e GIII com 500 vezes. (3A) Na micrografia do explante correspondente ao ponto biológico de 15 dias, é possível identificar individualmente os grânulos, áreas de contato e presença de poros intergranular. Defeito ósseo crítico foi preenchido com grânulos dispostos de forma aleatória. (3B) A micrografia do explante correspondente ao ponto biológico de 45 dias após o implante do novo biomaterial, com aspecto mais liso e uniforme. É possível diferenciar locais onde os grânulos foram depositados. (3C) Micrografia com 120 dias após o implante apresenta local com superfície lisa e uniforme, com conteúdo totalmente integrado na região que havia defeito ósseo crítico.
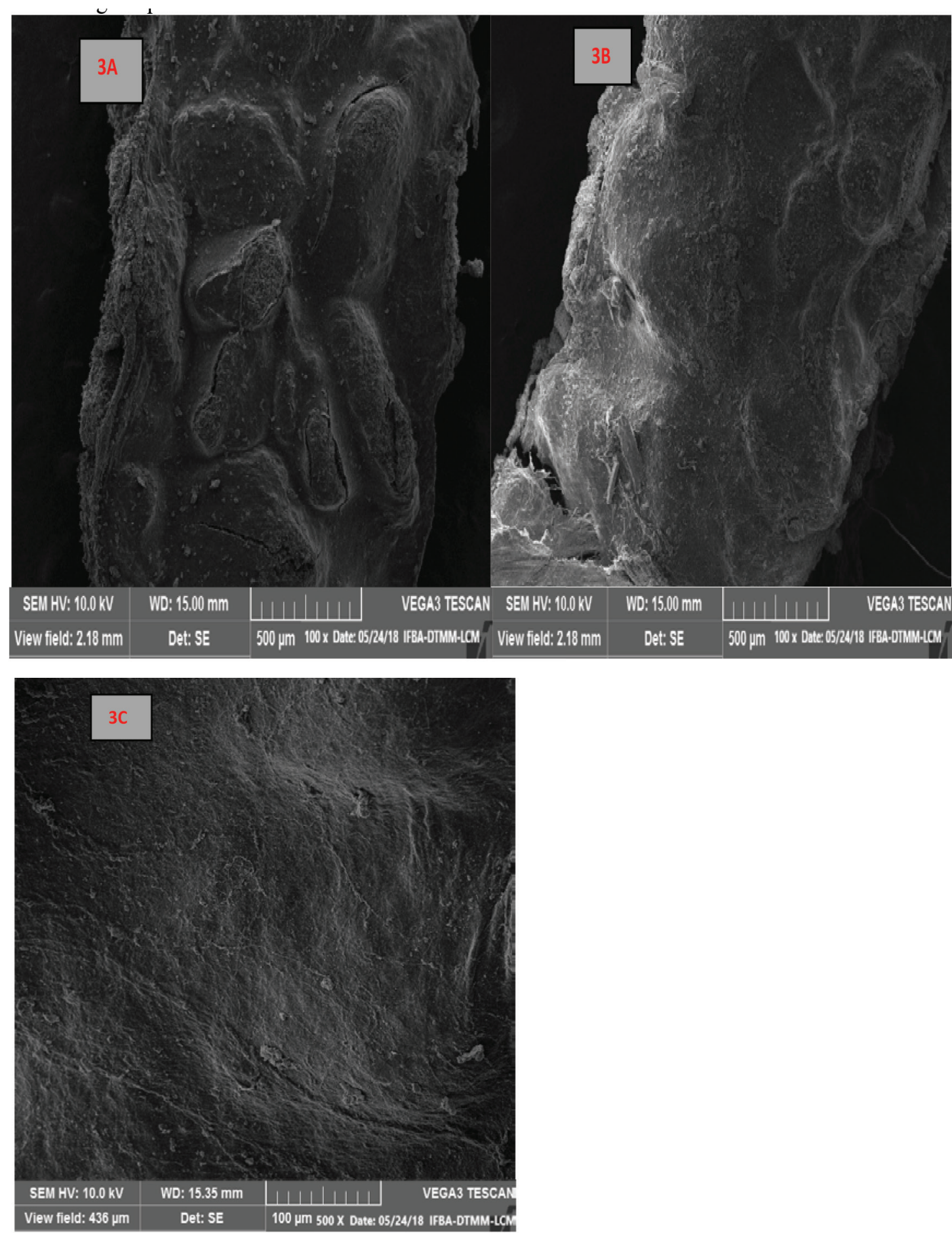

Fonte: Elaboração dos autores. 
Figura 4 - Micrografias com aumentos de 5.000 vezes da superfície do biomaterial composto de W e 6-TCP. (4A) Micrografia da superfície do biomaterial que não teve contato com tecidos e fluído biológico, mantendo aspectos das propriedades físicas do material. (4B) Micrografia da amostra com 15 dias após a implantação demonstrando mudanças físicas no formato das partículas e na porosidade do biomaterial, observa-se menor número de partículas e aumento do tamanho dos poros.

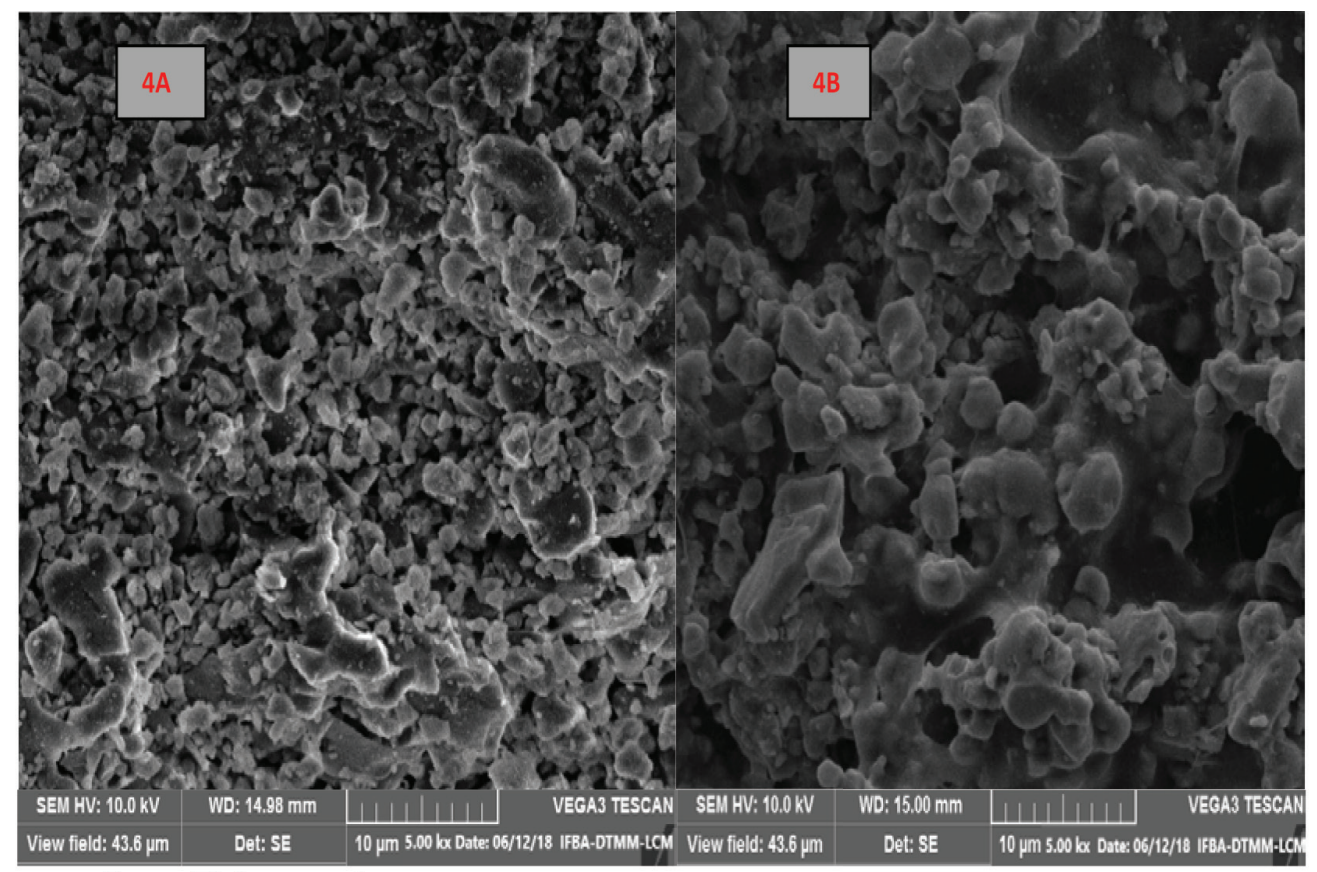

Fonte: Elaboração dos autores.

Figura 5 - Na sequência 5A, 5B e 5C demonstram imagens do grupo $G 0$, sendo 5 A imagem original, $5 B$ imagem com alto contraste para análise dos poros e $5 \mathrm{C}$ imagem de alto contraste para análise das partículas. Já a sequência 5D, 5E e 5F demonstram imagens do grupo Gl, sendo 5A imagem original, 5B imagem com alto contraste para análise dos poros e $5 \mathrm{C}$ imagem de alto contraste para análise das partículas.
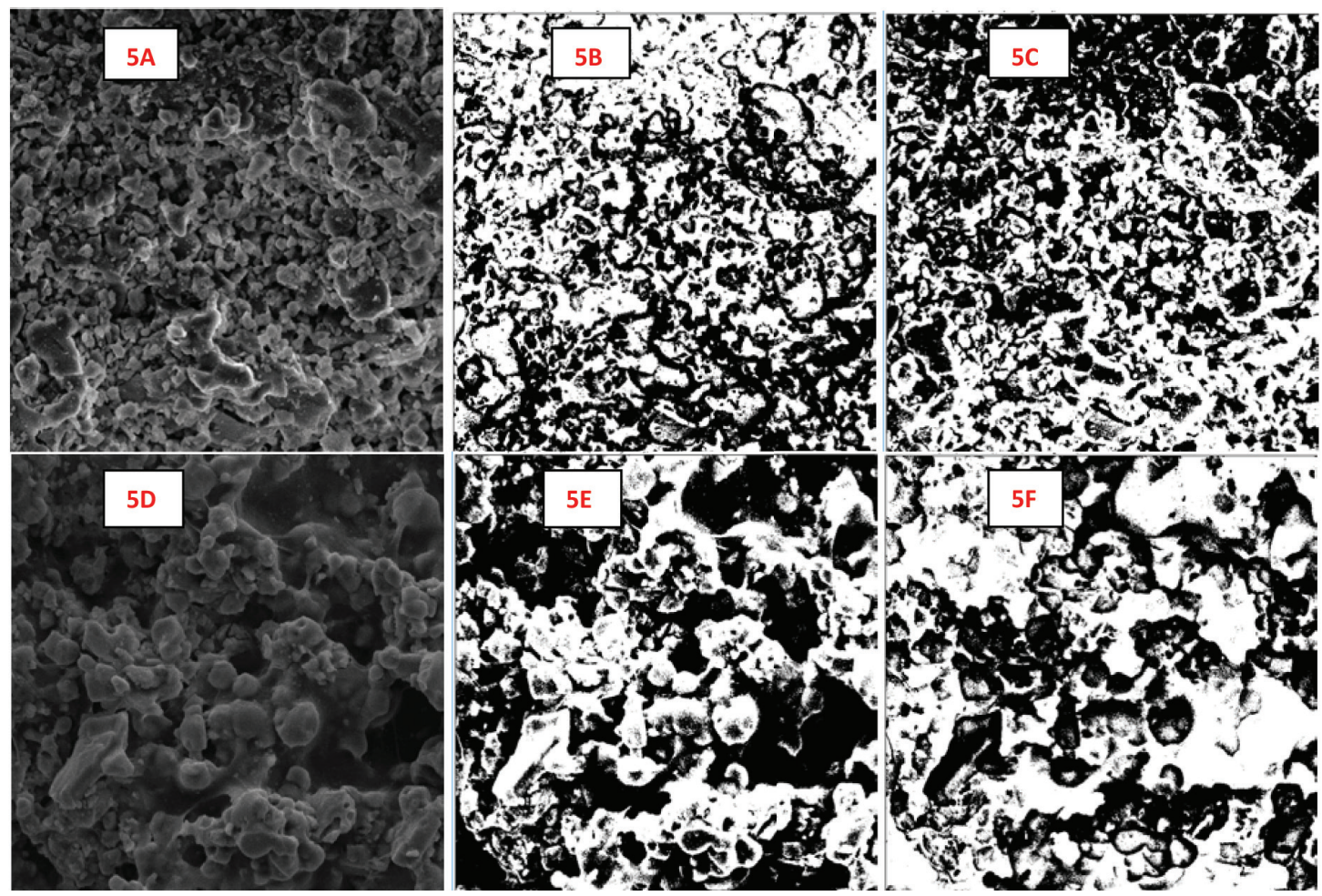

Fonte: Elaboração dos autores. 
O Quadro 1 apresenta a análise da área total da superfície da amostra, obtida pelo software, porcentagem da área ocupada por poros e por partículas do biomaterial em estudo. Trata-se de dados descritivos dos achados para os grupos $\mathrm{GO}$ e $\mathrm{Gl}$, relacionados com as mudanças nas dimensões das partículas e poros.

Quadro 1 - Resultados da análise da superfície do novo biomaterial em estudo com o software ImageJ.

\begin{tabular}{|l|c|c|c|c|}
\hline Amostras & $\begin{array}{c}\text { Área total } \\
\text { da amostra } \\
\boldsymbol{\mu m}^{2}\end{array}$ & $\begin{array}{c}\text { Área } \\
\text { ocupada por } \\
\text { poros (\%) }\end{array}$ & $\begin{array}{c}\text { Área ocupada } \\
\text { por partículas } \\
(\%)\end{array}$ & $\begin{array}{c}\text { Total } \\
(\%)\end{array}$ \\
\hline G0 & $1.879,86$ & 54.05 & 45.43 & 99.48 \\
\hline GI & $1.871,34$ & 56.00 & 43.13 & 99.13 \\
\hline
\end{tabular}

Fonte: Dados da pesquisa.
Para as amostras dos grupos GII e GIII (45 e 120 dias), não foi possível observar a porosidade característica do biomaterial com nova composição, por tratar-se de pontos biológicos onde componentes orgânicos recobriram os grânulos no local do implante. A Figura 6 apresenta micrografias dos explantes, onde o Gll apresentou partes dos grânulos do biomaterial em meio a componentes orgânicos. Nota-se a presença de microestruturas prologadas por toda extensão da superfície. Já no GIII, foi identificada a presença de uma camada praticamente contínua de componentes orgânicos contendo depósitos minerais de aspecto globular. Imagens desses dois grupos demonstraram aspectos relacionados à formação de nova matriz óssea na extensão do defeito ósseo crítico.

Figura 6 - Micrografias dos grupos Gll e GIII (45 e 120 dias). No grupo GII (6A), identifica-se o local que recebeu biomaterial coberto por componentes orgânicos, e presença de micros estruturas prologadas por toda superfície. Setas brancas indicam partes dos grânulos do biomaterial. Para GIII (6B), a micrografia deste grupo revelou a presença de uma camada praticamente contínua de componentes orgânicos contendo depósitos minerais de aspecto globular (setas vermelhas).

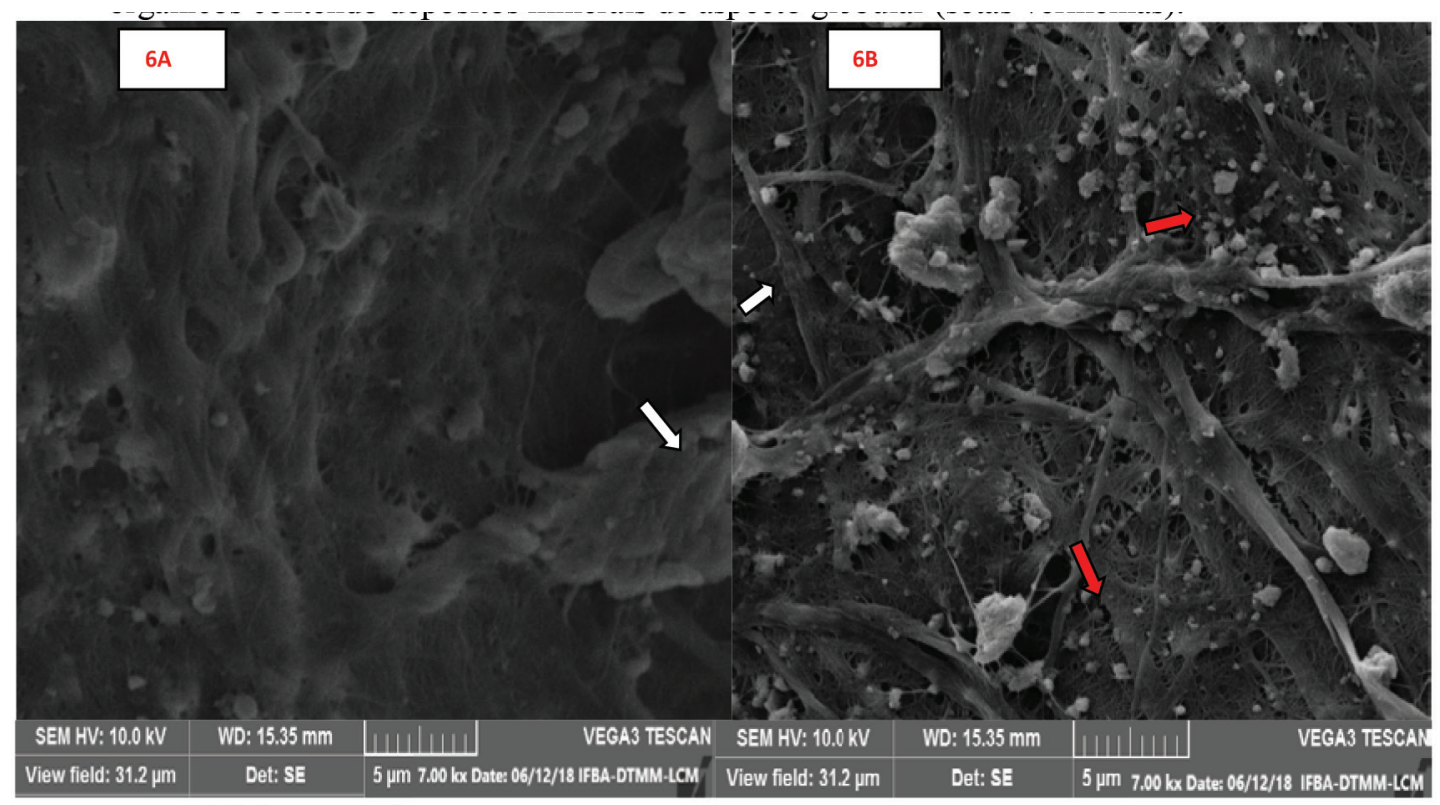

Fonte: Elaboração dos autores.

\section{DISCUSSÃO}

As modificações nas propriedades físicas do biomaterial com nova composição de W e $\beta$-TCP tornaram-se evidentes com o método de microscopia eletrônica de varredura nas amostras deste estudo. Destaca-se o formato dos grânulos vitrocerâmicos, na Figura 1, que no biomaterial são irregulares, multifacetados e angulares. Essas características no formato dos grânulos permitem a adaptação a qualquer geometria de defeito ósseo crítico. Os resultados demonstrados na Figura 2 podem ser associados às referidas características, pois verificou-se uma distribuição espacial uniforme dos grânulos do novo biomaterial compósito que promoveu preenchimento completo dos defeitos ósseos críticos. Segundo Saini et al. (2015), destacam que devem ser selecionados materiais que garantam uma distribuição mais uniforme do estresse mecânico, para haver condições favoráveis dentro do organismo vivo, e assim minimizar o movimento relativo na interface entre osso e o implante. Cabe destacar também que as formas granulares mantêm espaço entre as partículas, o que favorece a invasão da rede vascular, com aporte de substâncias/nutrientes para crescimento de tecido ósseo e consequente processo de reabsorção do implante (BOHNER et al., 2013). 
Com referência às dimensões, verificou-se na amostra do biomaterial com nova composição de W e $\beta$-TCP, grânulos com dimensões horizontais entre $400 \mu \mathrm{m}$ e 1.000 $\mu \mathrm{m}$, de acordo com as imagens da Figura 1. Embora a literatura não apresente um consenso para o tamanho ideal das partículas, entende-se que as dimensões dos grânulos do biomaterial se encontram entre os relatados pela literatura. Estudos verificaram resultados favoráveis para regeneração óssea com partículas de tamanhos próximos ao do presente estudo, como Coathup et al. (2013), que avaliaram o efeito do tamanho das partículas de um biomaterial composto de fosfato de cálcio e silicato para regeneração óssea, implantados em defeitos ósseos no côndilo femoral de ovino. $O$ referido estudo verificou que o defeito preenchido com grânulos entre 250 a $500 \mu \mathrm{m}$ apresentou formação óssea mais significativa em relação aos outros grupos que tinham partículas maiores, entre 1.000 e $2.000 \mu \mathrm{m}$, e partículas menores, entre 90 e 125 $\mu \mathrm{m}$. Concluíram que os grânulos de tamanhos entre 250-500 $\mu \mathrm{m}$ do referido biomaterial podem ser mais adequados para o tratamento de defeitos ósseos críticos.

No estudo de Eweida et al. (2017), entre outros fatores relacionados com a neovascularização e neoformação de tecido ósseo, analisaram um compósito a base de hidroxiapatita e sílica, com duas apresentações de tamanhos diferentes de partículas. Compararam-se compósitos com partículas de $200 \mu \mathrm{m}$ (pó), com partículas de $1.200 \mu \mathrm{m}$ em forma de grânulos. Após estudo in vivo com implantes subcutâneos em ratos, verificou-se que as partículas menores $(200 \mu \mathrm{m})$ proporcionaram resultados mais favoráveis em termos de vascularização e formação de tecido.

Quanto à porosidade, sabe-se que essa propriedade favorece o crescimento de novo tecido ósseo devido à colonização celular, neovascularização, migração e adesão de células osteoprogenitoras. Os resultados apresentados na Figura 4 permitem identificar as mudanças na porosidade superficial do biomaterial depositado no defeito ósseo crítico. Para o G0, sem contato com os tecidos e o fluido biológico, é possível identificar as micropartículas angulares interconectadas e abundância de microporos presentes na superfície dos grânulos do biomaterial. Já a micrografia da amostra do grupo GI permite identificar aumento nos tamanhos dos poros e a diminuição na quantidade das partículas menores, que compõem o grânulo.

Estes achados corroboram os encontrados por Costa et al. (2015), que estudaram a neoformação óssea e osteointegração de biomateriais micro e nanoestruturados em ovinos. Esse estudo comparou o aspecto da micrografia dos grânulos de hidroxiapatita previamente à deposição no defeito ósseo, com aspectos após aplicação no defeito ósseo proximal da tíbia direita de ovino, com 60 e 90 dias. Foi identificada alteração na morfologia, com perda das limitações de poros e vilosidades. As alterações na morfologia intragranular foi mais acentuada com maior tempo de implante nos respectivos pontos biológicos e relacionadas com a solubilização do biomaterial, quando em contato com os tecidos e o fluido biológico.

A presença e o tamanho de poros de um biomaterial influencia o comportamento celular. Hong et al. (2010), em um estudo que avaliou biomaterial poroso a base de fosfato de cálcio, associou resultados dos testes in vivo em cães, que receberam implantes do biomaterial em músculo dorsal e no fêmur, com uma cascata regular de atividades osteogênicas, que resultou em alta osteocondutividade e osteoindutividade.

Já o estudo experimental de Galois e Mainard (2004) verificou que, além da presença de porosidade, a composição química do biomaterial influencia a invasão e neoformação tecidual. Esse estudo comparou o comportamento da hidroxiapatita e do beta fosfato tricálcico, com diferentes tamanhos de porosidades $(45-80 \mu \mathrm{m}$, 80-140 $\mu \mathrm{m}, 140-200 \mu \mathrm{m}$, e 200-250 $\mu \mathrm{m}$ ), implantados em côndilos femorais de coelhos. Verificou-se que a hidroxiapatita, com porosidades menores $(45-80 \mu \mathrm{m})$, apresentou menor quantidade de osso neoformado nos diferentes tempos biológicos ( 2 semanas, 1 mês, 2 meses, 4 meses, 6 meses e 12 meses), em relação aos outros com maiores tamanhos de porosidade. Já o beta fosfato tricálcico, com menores tamanhos de porosidade, apresentou menor invasão óssea somente nos pontos biológicos inferiores a 4 meses, sendo que houve quantidade de osso semeIhante nos restantes tempos de implantação testados. No referido estudo, concluiu-se que substâncias com taxas de reabsorção maiores, como o beta fosfato tricálcico em relação à hidroxiapatita, permitiram no decorrer dos pontos biológicos a criação de espaços maiores para a invasão do novo tecido ósseo.

De acordo com estudo de Rumpel et al. (2006), biomateriais com poros dos tamanhos entre 100 e $500 \mu \mathrm{m}$, combinado com resistência mecânica, são eficientes para o processo de regeneração óssea. A conexão entre os poros facilita a invasão de células e vasos sanguíneos, no entanto, as desvantagens do material poroso são a dificuldade de uniformidade dos poros e a baixa resistência mecânica (GARCIA et al., 2015).

Também, cabe ressaltar, que estudos associaram biomateriais cerâmicos com poros de dimensões variadas, a maior eficiência na fixação, migração celular e formação de tecido em sua superfície. É evidenciado que a porosidade aumenta a formação vascular, fator fundamental para maior desempenho de um biomaterial implantado no preenchimento tecidual (HARRIS et al., 2013).

O Quadro 1 apresenta modificações na área ocupada pelos poros e pelas partículas no biomaterial com nova composição de W e $\beta$-TCP. Observou-se aumento na área ocupada pelos poros no grupo GI (56.00\%) em relação ao grupo G0 (54.05\%). Ao mesmo tempo, verificou-se que a área ocupada pelas partículas diminuiu no grupo GI (43.13\%) em relação ao G0 (45.43\%). Estes achados corroboram com estudos que acompanharam a degradação de biomateriais cerâmicos para regeneração óssea. Sabe-se que modificações físicas são importantes no processo de degradabilidade do biomaterial do tipo cerâmico para im- 
plantes ósseos. Esse processo deve ocorrer em equilíbrio com a formação do novo tecido, permitindo a formação de espaço onde o novo tecido vascular e ósseo deve ser formado. Os implantes para regeneração óssea devem apresentar taxas de degradação e formação do novo tecido, com uma transferência gradual de carga entre os componentes, para prevenir atrofiamento e estimular a remodelação a óssea (COSTA et al., 2015; SHEIKH et al., 2015).

Por isso, em nosso estudo, a análise das áreas ocupadas por poros e partículas na superfície dos grânulos permitiu quantificar mudanças nos percentuais de ocupação nos grupos $\mathrm{G} 0$ e $\mathrm{Gl}$ e relacioná-los com o processo de biodegradação, que entendemos ocorrer devido à solubilização do biomaterial, quando em contato com tecidos e o fluido biológico.

Por fim, as micrografias dos grupos GII e GIII da Figura 6 demonstram a área que recebeu o implante com presença de componentes orgânicos. O grupo GII apresentou partes dos grânulos do biomaterial em meio a componentes orgânicos, com presença de microestruturas prolongadas por toda extensão da superfície. Já no GIII, identificou-se a presença de uma camada praticamente contínua de componentes orgânicos, contendo depósitos minerais de aspecto globular. Estes resultados relacionados aos aspectos da formação de nova matriz óssea, na extensão do defeito ósseo crítico, estão de acordo com estudos que demonstram o potencial para regeneração óssea da W e do $\beta$-TCP (SHIE; DING; CHANG, 2011; PERERA et al., 2010; YE et al., 2012), corroborando os resultados obtidos no presente estudo.

Entende-se que a partir deste estudo exploratório, é necessário prosseguimento de um estudo com métodos específicos, para avaliação da neoformação tecidual no referido implante. E desta forma, obter maiores subsídios que possibilitem avaliar o potencial para regeneração óssea do biomaterial com nova composição de W e $\beta$-TCP.

\section{CONCLUSÃO}

Houve modificações físicas no formato, dimensões horizontais, distribuição espacial e porosidade da superfície dos grânulos do biomaterial, relacionadas com a biodegradabilidade e o potencial osteoindutivo e osteocondutor do biomaterial.

\section{AGRADECIMENTOS}

Agradecemos o Laboratório de Bioengenharia Tecidual e Biomateriais (LBTB/ICS/UFBA), o laboratório Helicon Medical S.L, o Consejo Superior de Investigaciones Científicas (CSIC), o Instituto de Cerámica y Vidrio (Madri-Espanha), ao Laboratório de Caracterização de Materiais do Instituto Federal da Bahia (LCM/IFBA), ao DTSBio/IFBA e o grupo de pesquisa de Tecnologia em Radiologia do IFBA, e à FAPESB pelo apoio e incentivo no desenvolvimento desta pesquisa.

\section{REFERÊNCIAS}

BOHNER, M. et al. Synthesis of spherical calcium phosphate particles for dental and orthopedic applications. Revista Biomatter, [ s.I], v.3, n. 2. Jun 2013.

CAMPOS, L. S. Regeneração de defeito ósseo crítico com novos arcabouços à base de monetita, hidroxiapatita e fases amorfas de fosfato de cálcio e sílica, dopados ou não com zinco. 2015. Tese (Doutorado em Processos Interativos dos Órgãos e Sistemas) - Universidade Federal da Bahia, Instituto de Ciências da Saúde, Salvador, 2015.

COATHUP, M. J. et al. The effect of particle size on the osteointegration of injectable silicate-substituted calcium phosphate bone substitute materials. J. biom. mater. res., Hoboken, v. 101, n.6. p. 902-910, Aug. 2013

CONZ, M. B. et al. Caracterização físico-química de 12 biomateriais utilizados como enxertos ósseos na Implantodontia. Implant News, São Paulo, v. 7, n. 4. p. 541-546, jul. 2010.

COSTA, B. D. et al. Neoformação óssea e osteointegração de biomateriais micro e nanoestruturados em ovinos. Pesq. vet. bras., Rio de Janeiro, v. 35, n. 2, p. 177-187, fev. 2015. Disponível em: <http://www.scielo.br/ scielo.php?script=sci_arttext\&pid=S0100-736X2015000200177\&lng=e n\&nrm=iso>. Acesso em: 18 ago. 2018.

DOROZHKIN, S. V. Calcium orthophosphates. J. mater. sci., London, v. 42, n. 4, p. 1061-1065, 2007.

EWEIDA, A. et al. The impact of various scaffold components on vascularized bone constructs. J. Craniomaxillofac. Surg., New York, v. 45. p. 881-890, June 2017.

GALOIS, L.; MAINARD, D. Bone ingrowth into two porous ceramics with different pore sizes: an experimental study. Acta Orthop. Belg., Bélgica, v.70, p. 598-603, 2004.

GARCIA-GARETA, E.; COATHUP, M. J.; BLUNN, G. W. Osteoinduction of bone grafting materials for bone repair and regeneration. Bone, New York, v. 81, p. 112-121, Dic. 2015.

Disponível em: <https://www.sciencedirect.com/science/article/pii/ S8756328215002793>. Acesso em: 5 maio 2018.

HARRIS, J. S. et al. A review of mouse critical size defect models in weight bearing bones. Bone, New York, v. 55, n. 1, p. 241-247, 2013.

HONG, Y. et al. Fabrication, biological effects, and medical applications of calcium phosphate nanoceramics. Mater Sci. Eng. R. Rep., Lausanne, v. 70, n. 3. p. 225-242, Nov. 2010.

MATSUMOTO, G. et al. Enhanced regeneration of critical bone defects using a biodegradable gelatin sponge and beta-tricalcium phosphate with bone morphogenetic protein-2. J. biomater. appl.,. Lancaster, v. 24, n. 4, p. 327-342, Nov. 2008.

PERERA, F. H. et al. Clarifying the effect of sintering conditions on the microstructure and mechanical properties of $\beta$-tricalcium phosphate. Ceram. Int., Italy, v. 36, n. 6. p. 1929-1935, Aug. 2010.

RUMPEL, E. et al. The biodegradation of hydroxyapatite bone graft substitutes in vivo. Folia morphol., Praha, v. 65, n. 1, p. 43-48, Feb. 2006.

SAINI, M. et al. Implant biomaterials: A comprehensive review. World J. Clin. Cases, Pleasanton, v. 16, n. 3, p. 52-57, Jan 2015.

SAINITYA, R. et al. Scaffolds containing chitosan/carboxymethyl cellulose/mesoporous wollastonite for bone tissue engineering. Int j. biol. macromol., Guildford, v. 80, p. 481-488, Sept. 2015.

SHEFFIELD, J. B. Image J, a useful tool for biological image processing and analysis. J. Micros. Microanal., New York, v. 13, n. 2. Aug, 2007. 
SHEIKH, Z. et al. Mechanisms of in vivo degradation and resorption of calcium phosphate based biomaterials. Materials, Basel, v. 8, n. 7. p. 913-925, Nov. 2015.

SHIE, Ming-You; DING, S. J.; CHANG, Hsien-Chang. The role of silicon in osteoblast-like cell proliferation and apoptosis. Acta biomater., Oxford, v. 7, n. 6. p. 2604-2614, Jun. 2011.

TAYLOR, E. D.; KHAN, Y.; LAURENCIN, C. T. Tissue engineering of bone: A primer for the practicing hand surgeon. J. Hand Surg. Am., New York, v. 34, n.1, Jan. 2009.

Submetido em: 01/02/2019

Aceito em: 07/10/2019 